\title{
Expanding Capacity to Serve Multilingual Learners: A University-School District Partnership
}

\author{
Excelsior: Leadership in \\ Teaching and Learning \\ 2018, Vol. 11(1) 31-41 \\ (C) The Authors 2018 \\ CC-BY 4.0 International \\ Reprints and permissions: \\ surface.syr.edu/excelsior \\ https://doi.org/10.14305/jn.1 \\ 9440413.2018.11.1.03 \\ nyacte.org

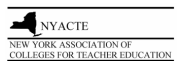

\section{Beth Clark-Gareca ${ }^{1}$ and Kim Fontana ${ }^{2}$}

\begin{abstract}
In a time of new teacher certification requirements in New York State, school districts are grappling with how to meet the regulatory expectations imposed by Commissioner's Regulations Part 154. One way that schools are solving staffing challenges is by forging new collaborations with university partners to expand their collective capacities to serve Multilingual learners (MLLs). In this article, we document a partnership between SUNY New Paltz's Teaching English to Speakers of Other Languages (TESOL) program and the Pawling Central School District during the 2017-18 academic year. We describe the partners' distinct roles in the university-district collaboration, and discuss the logistical considerations and challenges they faced, with respect to program design, hybrid instruction, meeting certification requirements, and working with established university systems. We conclude by identifying components that ultimately made the partnership a success.
\end{abstract}

\section{Keywords}

Partnerships, ELLs, TESOL, School Districts, Certification

Educating multilingual learners $\left(\mathrm{MLLs}^{3}\right)$ in K-12 contexts is changing in New York. A marked increase in the number of children needing English language support in school has been the impetus for new

\footnotetext{
${ }^{1}$ State University of New York at New Paltz

Corresponding Author:

Beth Clark-Gareca, Department of Teaching and Learning, School of Education, SUNY New Paltz, 800 Hawk Drive, New Paltz, NY 12561.

Email: garecab@newpaltz.edu

2 Pawling Central School District

${ }^{3}$ We use the preferred New York State term multilingual learners (MLLs) to refer to learners of English, English Language Learners or English Learners.
} 
English as a New Language (ENL) ${ }^{4}$ regulations across the state. These regulations, coupled with the greater number of identified MLLs as a whole, have created a need for more certified teachers in school districts throughout the state.

Recent statistics suggest that about $9 \%$ of all students in New York are in the process of learning English, and of those students, $63 \%$ are newcomer students who have been in New York schools for fewer than three years (NYSED, 2017). Apart from newcomers, many other identified MLLs are not immigrants, but are US citizens, having been born in the United States. In fact, a nationwide study suggests that more than half of all currently identified MLLs in U.S. schools were born in the US (Zong \& Batalova, 2015). Without a doubt, children in United States public schools are steadily becoming more multilingual, resulting in new challenges, and new opportunities, for the public school systems that educate them.

To give some background on the current state regulations, in 2015, the New York State Department of Education (NYSED) implemented new mandates outlining instruction, assessment, and educational protections for MLLs and their families. Commissioner's Regulations (CR) Part 154 was operationalized through the Blueprint for English Learners, and extended specific, explicit requirements for MLL instruction based on students' developing proficiency levels (NYSED, 2016). These state mandates stipulate that MLLs' linguistic needs must be supported through instruction from teachers with expertise in the areas of ENL and/or bilingual education.

Since CR Part 154 was enacted, most school systems have had to adjust, reallocate, and intensify the services offered to MLLs in their buildings. Some school districts, and more specifically, individual schools, have been put in a difficult position - they are in urgent need of more ENL teachers on staff, but have not been able to fill available positions because of a dearth of ESOL certified teachers in the employment pool. This is the case even for schools that have not experienced a surge in MLLs in attendance, but where CR Part 154 alone has triggered a shortage in service provision.

One way that school districts have solved the staffing challenges of CR Part 154 is by creating opportunities for their current teachers to pursue ESOL as an additional certification. By encouraging working teachers to undertake and complete these requirements, school districts solve multiple problems at the same time; 1) They create capacity for instruction within their current staff to meet current MLLs' needs, 2) they prepare their staff for future MLLs who may join the school district in years to come, and 3 ) they encourage their teachers' exposure to current research, theory and practice in linguistics and social justice education. The latter is especially important in suburban districts with a stable workforce of teachers who are sometimes many years removed from their graduate studies.

Preparing a cohort of working, content teachers for ESOL certification requires a strong partnership between university and school district stakeholders. Such partnerships can yield unique rewards by helping teachers to meet the needs of MLLs in their own educational contexts, while simultaneously preparing these same teachers to work with MLLs in any context. In the next section, we examine the literature related to school partnerships as it relates to the Pawling Central School District (PCSD)SUNY New Paltz TESOL project.

\footnotetext{
${ }^{4}$ Throughout this article, we use the term ENL (English as a New Language) to refer to all aspects of the field, including ESL (English as a Second Language) and ELD (English Language Development). We use the term ESOL (English to Speakers of Other Languages) to refer to the certification area.
} 


\section{School Partnerships}

The benefits of school-university partnerships are well documented within the teacher education literature (Hunter \& Botchway, 2017; O'Neal, Ringler, \& Lys, 2009; Sherritz, \& Kyle, 2011; Valenciana, Morin, \& Morales, 2005). Partnerships between university teacher preparation programs in institutes of higher education (IHEs) and local education agencies (LEAs) in the form of public schools have been the focus of a variety of studies, particularly within the field of special education (Gutierrez \& Sobel, 2011; Maheady \& Magiera, 2017; McCray, et al., 2011, Rosenberg \& Rock, 1994; Rosenberg, et al., 2009). In their oft-cited study of an alternative certification project, Rosenberg and Rock (1994) explored a special education partnership program where they closely delineated the necessary relationships between IHEs, LEAs, and state departments of education to make these programs effective. They concluded that their project contributed, "to the on-going national debate concerning the efficacy and merits...of nontraditional routes to teacher education" (Rosenberg \& Rock, 1994, p. 151).

The debate that Rosenberg and Rock (1994) identified certainly continues on a national level in the field of ENL as well. Unlike in special education, however, the literature related to nontraditional schooluniversity partnerships in an ENL context is quite sparse, and tends to focus on professional development initiatives rather than certification pathways. The literature included here discusses various partnerships that were established to further the collaborative goals in both university and school settings.

Two relevant ENL partnership studies have focused on the ways that teachers can create language development opportunities for MLLs in class (Gebhard \& Willett, 2008; Shea, Sandholtz, \& Shanahan, 2017). Gebhard and Willett (2008) found that content teachers were able to improve their use of academic language for MLLs' benefit through a sustained professional development series. Shea, Sandholtz, and Shanahan (2017) studied a university-school district partnership in which teachers were encouraged to rethink the ways that they infused classroom talk into their lessons for the benefit of MLLs. These studies highlight the positive effect that partnerships can have on teachers' developing techniques and pedagogies related to ENL.

Other research studies examined ENL partnerships through a wider lens, including teachers' attitudes towards MLLs, (Walker-Dalhouse, Sanders, \& Dalhouse, 2009) and teachers' development of more multi-faceted instructional practices (Williams, Diaz, \& Worthen, 2017). In their study of an ENL university-district partnership, O'Neal, Ringler, and Lys (2009) documented a professional development community involving partners from university and federal programs, as well as principals and teachers. The researchers noted they were able to achieve what they identified as hidden goals, "to re-energize teachers, create ownership in the learning community, and to nurture a new sense of collegiality and leadership within the schools" (O'Neil, Ringler, and Lys, 2009, p. 54). In another study, Israel, Goldberger, Vern, and Heineke (2017) described positive outcomes of a university-multi school district collaboration on behalf of immigrant and migrant students where the collaboration focused on teacher leadership, parent involvement, and equitable, culturally responsive education for all students.

In light of CR-Part 154, school-university partnerships are taking on new importance in the state of New York. As the need for ESOL certified teachers increases, grant funding has been made available through NYSED to encourage the development of alternate certification pathways in lieu of the traditional ones offered through IHEs (NYSED, 2018). In most of these programs, teachers, schools, and universities have expressed a mutual benefit from these academic collaborations.

On the university side, professors and researchers reported enjoying having contact with real K-12 contexts and maintaining an accurate, immediate understanding of what is really happening in schools. 
Shambaugh (2011) documents the importance of these real experiences for university partners, stating that designating a university liaison to work between educational settings can help to ensure that these partnerships are maximally beneficial for researchers and teachers alike.

On the K-12 school side, teachers report the benefit of taking a wider view of the field of education outside their own classrooms. They grow from their course readings and assignments that demand a new, critical analysis of the systems that they work in every day. Also, administrators benefit by forging relationships with schools of education; these relationships have ongoing potential for spawning other opportunities for students and educators within the school district, e.g., creating sites for research, deepening collaborations with respect to student teacher internships, university-provided professional development outside of the specific course sequence, and the joint authorship of papers such as this one.

In any university-school collaborations, the partners typically have a strong, common interest in the participants' successful completion of the program and eventual certification. Next, we examine the specific context of the Pawling Central School District (PCSD) and SUNY New Paltz's TESOL partnership, insofar as it represents a successful cohort partnership model for ESOL certification in New York.

\section{Pawling-SUNYNew Paltz Partnership Model}

During the 2017-18 academic year, the TESOL Program at SUNY New Paltz and the administration at the Pawling Central School District ventured into a joint effort to certify Pawling teachers in ESOL. In the next sections, we explore each educational entity, SUNY New Paltz and Pawling Central School District, to understand the unique benefits that each partner brought to shape this effective collaboration.

Teacher education at the State University of New Paltz. Teacher education has long been a part of SUNY New Paltz's history. In 1885, the State University of New Paltz first began its mission of teacher preparation, and in 1942, it changed its name to "The State Teachers College at New Paltz" to reflect the institution's strong commitment to undergraduate teacher education (New Paltz, 2018). Today, SUNY New Paltz's School of Education confers undergraduate and graduate degrees in a variety of disciplines, including, but not limited to: Early Childhood/Childhood Education, Adolescence Education, Literacy, Special Education, and Teaching English to Speakers of Other Languages (TESOL).

As teacher licensure processes become more complex in New York, SUNY New Paltz's TESOL program has worked to create new specialized, teacher certification pathways to meet the educational needs of the community it serves. These programs are targeted toward teachers at the post-Masters level, who already hold professional or permanent certification in a content area, and who are interested in expanding their skill set to meet the needs of ENL populations in schools. For example, through a Certificate of Advanced Study (CAS) program, a professionally certified $8^{\text {th }}$ grade mathematics teacher can become a more effective teacher of MLLs in math class by pursuing an additional ESOL certification.

Traditionally, teacher preparation classes at SUNY New Paltz have been taught on campus in New Paltz in person. However, to meet the needs of $21^{\text {st }}$ century students, SUNY New Paltz is offering courses in more flexible ways. The CAS in TESOL incorporates an intensive course format by creatively utilizing longer, but fewer class meetings to fulfill the required number of contact hours per credit. Hybrid courses reduce the number of in-person sessions and ease scheduling difficulties for busy, working teachers, thereby promoting more opportunities for participants to individually manage their own time. 
In CAS hybrid courses, in-person class meetings usually take place away from the college campus in a more central location to where the participants work or live, e.g., an available school district classroom. Not requiring students to travel to the college increases convenience for working teachers exponentially; the elimination of travel time is often what allows teachers to participate at all. Off-campus courses have expanded the geographical reach of SUNY New Paltz and have allowed us to recruit students outside of the normal geographical reach. Also, by state statute, offering courses off campus allows the university to reduce the tuition costs for students or institutions, thereby making the programs more financially feasible for participants. These factors have contributed positively to SUNY New Paltz's TESOL program, and helped to lay important groundwork for the ENL partnership forged with PCSD.

English as a New Language in Pawling Central School District. Pawling Central School District is located in Pawling, New York, and is one district that has been impacted by slowly increasing numbers of MLLs; nonetheless, the greatest change the district has experienced stems from the mandates in CR Part 154. In 2013, the district was adequately served by 2.5 full-time equivalent ESOL certified teachers with approximately 40 students receiving services. Currently, there are four full-time ESOL-certified teachers and 63 students receiving services, representing a significant increase in the services offered to our MLLs.

To illustrate this point more clearly, consider the following scenario: In 2013, in Pawling, an entering or emerging MLL might have had English language instruction with the ENL teacher in a pullout setting. This instruction might have taken place in the company of other MLLs at similar proficiency levels, who were not necessarily in the same grade or even in adjacent grades. For example, at that time, three emerging students in grades $\mathrm{K}, 2$, and 4 could have received ENL instruction together, in one group, at the same time.

Following the adoption of the Blueprint for ELLs in New York State, ENL services for MLLs have been significantly changed and intensified (NYSED, 2016). Now, these three MLLs, despite being at similar proficiency levels, cannot receive instruction together on account of their non-adjacent grades (K, 2 , and 4). These students now benefit from dedicated instruction from the ENL teacher in separate, grade level (or adjacent grade level) bands.

Further, these same three students, under the Blueprint, now receive an additional full period of specialized instruction in their integrated English language arts class, supported by the ENL teacher through a co-teaching model. Since these students have three different English language arts classes, the ENL teacher now spends an additional three periods of his/her day in integrated instruction.

To sum up, before the Blueprint, a given ENL teacher could have met the regulatory expectations for these three MLLs in a single period. The new reality for New York school districts is that these same three students now need six, separate periods of the ENL teacher's time. The consequence of these mandates is that many more hours of an ENL teacher's day are consumed by CR Part 154 - Blueprint aligned instruction. The district's obligation for full-time equivalence (FTE) has increased six fold without any change in the number of students served.

When PCSD went to recruit the new ENL teachers that the district needed to comply with the revised CR Part 154 regulations, administrators encountered a very shallow pool of qualified teachers to hire. They also knew they had virtually no flexibility or capacity within their existing staff to meet the important challenges they faced. Upon consideration, they looked to the option of a university partnership to address their needs and concerns, and reached out to SUNY New Paltz in the hopes that such a relationship might be mutually beneficial. 


\section{Implementation of ESOL Advanced Certification Program 2017-18}

In the spring of 2017, the assistant superintendent and director of pupil personnel of PCSD approached SUNY New Paltz to forge a partnership designed to certify employed content teachers in the PCSD in ESOL. This initiative was embarked upon to fulfill two primary goals: 1) To improve capacity in all of the school district's schools to meet the educational needs for existing MLLs in regular classrooms where they spend the vast majority of their day, and 2) to prepare for expected, incoming MLLs with ready systems in place. A meeting took place at SUNY New Paltz where representatives from PCSD and New Paltz's School of Education, including the authors of this paper, discussed the needs of PCSD. In that meeting, we analyzed what assets each party brought to the partnership, considered any capacity constraints of either institution or the State, and determined what questions still needed to be answered to move forward with programming and curricular decision-making.

\section{Logistical Considerations and Challenges}

Several considerations and challenges surfaced in the process of designing the Pawling -New Paltz ESOL certification program. Four components of the program, including overall design, hybrid course platforms, certification requirements, and university systems were identified and are discussed next.

Design of program/courses. The partners agreed to a five course, 15 -credit program which would lead to ESOL certification. In collaboration, we decided that we would offer the program to interested Pawling teachers during the 2017-18 calendar year. We purposely scheduled the classes around PCSD's scheduled breaks and vacations, as well as aligning summer courses to coincide with the dates of PCSD's summer MLL enrichment program. This overlay with the summer program afforded participants real clinical opportunities to work with elementary MLLs who were in the process of developing English proficiency.

Despite the intensive, compressed nature of the program, the university strived to maintain academic rigor by creating courses that were on par with other graduate courses offered at SUNY New Paltz. Deliberate attention was paid in the design phases to create and differentiate graduate coursework from professional development programs that teachers had taken part in frequently in the past. To create this distinction, textbooks were required for each course, and were purchased for the participants by PCSD. Multiple course readings and media assignments were made available on Blackboard, SUNY New Paltz's online course management site, to support the distance component of the course. Students were required to complete discussion boards, weekly response tasks, and several large projects and assignments for each course. Final exams were also required at the end of some of the courses which provided participants with opportunities to demonstrate their learning in concrete ways, as well as an additional accountability structure for the material covered.

Course 1 began in July 2017 during PCSD's MLL summer session, and Course 5 concluded in July 2018, again during the MLL summer session. The three other courses were offered in hybrid format during the school year, running from September - October, 2017 (Course 2), from November-January 2018 (Course 3), and from March to May, 2018 (Course 4). The hybrid courses are more fully described in the following section. 
Hybrid delivery mode. To create more flexibility for busy, working teachers, three of the required courses were offered in hybrid fashion. Each of these courses had two in-person meetings - the first and the last class - and then four intervening online modules that were completed over the duration of the course.

The in-person classes were used to conduct activities that lent themselves to being physically present. In-person classes were frequently dedicated, in part, to exchanging important course and programmatic information. The first class was usually spent introducing the course, the assignments, giving an overview of the course material, and giving groups time to organize for future assignments. The last classes were frequently dedicated to students taking examinations or presenting final, individual, or group projects. Through face-to-face interactions, participants developed a strong sense of cohort with their colleagues (some of whom did not know each other before beginning the program), and built a collective vision for MLLs in their schools.

The in-person classes were conducted on PCSD's campus for the convenience of the participant teachers who lived and worked in the Pawling area. The district provided classroom space for the inperson courses to be conducted on Saturdays, absorbing any additional custodial costs in return for the convenience offered to the teachers.

The intervening online modules required participants to complete tasks related to course materials, and interact with their colleagues through participation in discussion boards. Weekly deadlines and submission times for all assignments were established so as to keep the courses on track. This group of participants was notably tech savvy which likely stems from the fact that PCSD as a district has embraced technology, and has infused it thoughtfully into their own classrooms, both through providing a one-toone Chromebook environment for students and also extensively using Google apps for education. Many anticipated challenges that we expected in the online delivery of instruction simply did not arise, which is largely attributable to the technological comfort and skill level of the teachers.

Fulfilling certification requirements. To be certified in ESOL by NYSED, candidates must take twelve credits of undergraduate coursework in a language other than English. For some participant teachers - like certified World Language teachers - this requirement did not present any problem because they had already taken these credits in their undergraduate programs. For other participant teachers, however, completing these credits presented a distinct challenge, in that to be eligible for ESOL certification, they needed to take language classes in addition to their graduate classes. For those who needed to fulfill this requirement, these language courses significantly increased the number of courses they needed to take before applying for their ESOL certification.

Participants also needed to take and pass the New York State Content Specialty Test (CST) in ESOL. This examination is required by NYSED to ensure that candidates have developed a mastery of the concepts related to many aspects of the field of TESOL. We encouraged participants to schedule the test toward the end of the program, and provided some test materials to aid in their preparation for the exam. Participants were also required to complete a series of workshops, including the Dignity for All Students Act (DASA). Some participants who had become certified in their content area recently had already satisfied this requirement; others were in the position of scheduling and completing these workshops through SUNY New Paltz or another local provider.

Instructors. For the program to run smoothly, SUNY- New Paltz needed to find instructors who had experience teaching online. Online learning is still a relatively new innovation in course delivery, and many part-time instructors in SUNY New Paltz's adjunct pool were not yet qualified to meet the instructional demands of this kind of intensive, hybrid program. To ensure that the pedagogical level was 
appropriate and suitable for the participants' needs, the coordinator of SUNY New Paltz's TESOL program taught most of the courses. As our educational world becomes increasingly connected through online platforms, SUNY-New Paltz is exploring ways to further capacitate our part-time faculty to work more effectively in online and hybrid contexts.

In addition, though convenient for participants, offering the courses in Pawling, approximately 30 miles from New Paltz, presented a challenge for the TESOL program to find adjunct instructors who were willing to travel that distance to teach. For the hybrid courses, the online component minimized the number of in-person instructional days, but for the summer school aligned courses (Courses 1 and 5), an instructor needed to travel to Pawling five days a week for the duration of the program.

Testing university-wide systems. In launching a new program like the Pawling-SUNY New Paltz partnership, university departments that typically work together in smooth, predictable ways are inadvertently tested for their flexibility and responsiveness.

A challenge that the Pawling-SUNY New Paltz partnership faced from the start was that our collaboration did not easily adhere to established, university procedures. For example, at SUNY New Paltz, university calendar triggers automatically let students know when to pay or register for the next course, or when to complete Student Evaluation of Instruction (SEI) surveys at the end of a term. Because our classes were designed primarily around PCSD's academic calendar and did not follow the semester format at SUNY New Paltz, the calendar triggers that we needed did not always coincide with the regular, college calendar, resulting in university systems needing to be modified significantly to accommodate alternate pathways and provide alternate triggers. Some areas of modification of procedures included: a) newly designed admission processes for CAS certification cohorts, $b$ ) alternate registration and payment workflows through a third-party provider, c) on-going, off-semester access to the online learning platform, Blackboard, and d) different timelines for submitting course grades and SEI evaluations.

Several formal meetings were convened at SUNY New Paltz to share information about new processes with various college entities, e.g. Information Technology, Records and Registration, and the Office of Graduate and Extended Learning. Many key people within the university and in the school district worked in professional collaboration throughout the year to modify traditional processes toward a goal of a smooth, newly invented workflow processes.

\section{Key Components to a Successful Partnership}

Partnerships are only worthwhile if each partner benefits from the collaboration in meaningful ways. In this case, both partners, SUNY New Paltz and PCSD, believe that this effort was successful as measured against their own goals for the program.

From the district's perspective, the measure of the program is that eleven teachers began the coursework and eleven teachers are slated for certification. The overall goal of capacitating the current faculty of PCSD has been realized, and future, potential staffing difficulties based on numbers of incoming MLLs and constraints of service provision, have likely been mitigated, if not averted entirely.

The school district recognizes that geography was critical in reaching this goal. Holding the courses on the district campus made it possible for teachers who would not have likely mounted the effort to attend on-campus courses at SUNY New Paltz to continue their education. The expertise of the program director and the commitment of the School of Education administration to the partnership were essential to students remaining engaged in the coursework. Flexibility to solve problems in creative ways, and 
patience to negotiate and communicate new processes were surely a critical factor on the part of both institutions.

The district significantly incentivized the program for participant teachers. First, the district paid for the five-course sequence directly, as well as the required texts, and also reimbursed participants for required certification examinations. Upon attaining certification, the district will also compensate the teachers through graduate credit. Doing so actually required the district to enter into a specific memorandum of agreement with the teachers' association because paying for graduate study and awarding salary benefits for the same appeared to be prohibited by existing contract language. The district also situated the program as a strategy within two of its district goals: to improve instruction in literacy and to create and sustain inclusive and welcoming school environments. Making the program a prominent component of district improvement efforts assisted the district in garnering the support of the Board of Education.

From the university's perspective, when graduate enrollments in the field of education are nationally on the decline, working with a committed, group of graduate students for a five-course sequence is a welcome prospect. The School of Education was pleased to design the program for Pawling in a format that was manageable for them, within the parameters set by the graduate school and by the State.

Having the opportunity to work with a cohort of teachers, all with a strong, collective commitment to the students in Pawling Central School District, was especially powerful in that it allowed specific, local concerns to be identified and addressed. For example, Pawling participants identified areas within their schools that would benefit from more bilingual signs, and they created an opportunity for their MLLs to conduct the translations and create the signs. This kind of impact on the district and its students was seen as a very positive outcome.

Additionally, PCSD's financial and professional support for the participants was a key in the program's successful implementation. The commitment of Pawling's administration, coupled with the initiative from the college to create a new, innovative program, was necessary for this program to come to fruition.

It should not be forgotten that the purpose of partnerships like the one between SUNY New Paltz and the Pawling Central School District is to benefit students directly and significantly. Partnerships like this one have the potential to positively affect the capacity of each institution to improve educational outcomes for its respective students. This partnership had an immediate impact on the students in PCSD's summer school, as well as on all the MLLs in the classrooms of the participant teachers. With new expertise and knowledge about the field of ENL, the teachers brought a new-found enthusiasm for assisting MLLs to their schools, and will continue to be a resource and assets for these students going forward..

As the numbers of MLLs continue to increase in the state of New York, partnerships such as this one can serve as one model toward solving the problem of finding dedicated, expert teachers for culturally and linguistically diverse students. Increasing capacity for ENL instruction across the state through university-school district partnerships can have lasting effects to meet the educational needs of MLLs today, and far into the future.

\section{Declaration of Conflicting Interests}

The authors declared no potential conflicts of interest with respect to the research, authorship, and/or publication of this article. 


\section{Funding}

The authors received no financial support for this research.

\section{References}

About New Paltz: History of the campus. (n.d.) Retrieved from http://www.newpaltz.edu/about/history.html.

Gebhard, M. \& Willett, J. (2008). Social to academic: University-school district partnership helps teachers broaden students' language skills. Journal of Staff Development, 29(1), 41-45.

Gutierrez, C. \& Sobel, D. (2011). Building capacity for a merged general and special education teacher preparation program in professional development schools. In J. Nath, I. Guadarrama, \& J. Ramsey (Eds.), Investigating university-school partnerships. (pp. 423-443). Charlotte, NC: Information Age.

Hunter, P.E. \& Botchwey, N.D. (2017). Partnerships in learning: A collaborative project between higher education students and elementary school students. Innovative Higher Education, 42(1), 77-90. https://doi.org/10.1007/s10755-016-9363-x

Israel, M., Goldberger, N., Vera, E., \& Heineke, A. (2017). An unlikely destination: Meeting the educational needs of immigrant, migrant, and refugee children in the suburbs of Chicago, IL. International Journal of Educational Management., 31(5), 580-597. https://doi.org/10.1108/IJEM-09-2016-0190

Maheady, L. \& Magiera, K. (2017). Building and sustaining school-university partnerships in rural settings: One approach for improving special education service delivery. Rural Special Education Quarterly, 35(2), 33-40. https://doi.org/10.1177/875687051603500205

Nath, J., Guadarrama, I. \& Ramsey, J. (Eds.). (2011). Investigating university-school partnerships. Charlotte, NC: Information Age Publishing.

New Paltz College History Timeline (n.d.) Retrieved from https://library.newpaltz.edu/collections/special/timeline.html.

New York State Education Department (2016). Blueprint for English Language Learners. Retrieved from http://www.nysed.gov/common/nysed/files/programs/bilingualed/nysblueprintforellsuccess.2016.pdf

New York State Education Department (2017). MLL demographics \& performance 2015-2016. Retrieved from http://www.nysed.gov/common/nysed/files/ell demographicperformance 2017-ver1516.pdf.

New York State Education Department (2018). Pathways to teacher certification: Alternative teacher preparation program. Retrieved from http://www.highered.nysed.gov/tcert/certificate/rightpathway.html

O'Neal, D., Ringler, M., \& Lys, D. (2009). Skeptics to partners: University teams with districts to improve ELL education. Journal of Staff Development, 30(4), 52-55.

Penner-Williams J., Diaz, E. \& Worthen, D. (2017). PLCs: Key PD component in learning transfer for teachers of English learners. Teaching and Teacher Education, 65, 215-229. https://doi.org/10.1016/i.tate.2017.03.014

Rosenberg, M. \& Rock, E. (1994). Alternative certification in special education: Efficacy of a collaborative, field-based teacher preparation program. Teacher Education and Special Education, 17(3), 141-153. https://doi.org/10.1177/088840649401700302 
Rosenberg, M.S., Brownell, M., McCray, E, deBettencourt, L.U., Leko, M. \& Long, S. (2009). Development and sustainability of school-university partnerships in special education teacher preparation: A critical review of the literature. (NCIPP Doc No: RS-3). Retrieved from http://ncipp.education.ufl.edu//files 6/NCIPP Partner 010310.pdf.

Shambaugh, N. (2011). Learning from public schools: Recommendations from 10 years as a university liaison. In J. Nath, I. Guadarrama, \& J. Ramsey (Eds.), Investigating university-school partnerships. (pp. 233-247). Charlotte, NC: Information Age.

Shea, L. Sandholtz, J., \& Shanahan, T. (2017). We are all talking: a whole-school approach to professional development for teachers of English learners, Professional Development Education, 44(2), 190-208. https://doi.org/10.1080/19415257.2016.1274267

Sherritz, C. \& Kyle, D. (2011). Improved learning for all partners: A school/university partnership for teacher preparation, teacher development and student achievement. In J. Nath, I. Guadarrama, \& J. Ramsey (Eds.), Investigating university-school partnerships. (pp. 389-402). Charlotte, NC: Information Age.

Valenciana, C. Morin, J.A., \& Morales, R. (2005). Meeting the challenge: Building university-school district partnerships for a successful career ladder program for teachers of English learners. Action in Teacher Education, 27(1), 82-91. https://doi.org/10.1080/01626620.2005.10463376

Walker-Dalhouse, D., Sanders, V., \& Dalhouse, A. (2009). A university and middle-school partnership: Preservice teachers' attitudes toward ELL students. Literacy Research and Instruction, 48(4), 337-349. https://doi.org/10.1080/19388070802422423

Zong, J. \& Batalova, J. (2015). The Limited English Proficient population in the United States. Washington, DC: Migration Policy Institute. Retrieved from https://www.migrationpolicy.org/article/limited-english-proficient-population-unitedstates\#Age, \%20Race, \%20and\%20Ethnicity 